\title{
GASTO PÚBLICO, FISCALIZACIÓN Y ADMINISTRACIÓN DE RECURSOS ECONÓMICOS PÚBLICOS
}

\author{
PUBLIC EXPENDITURE, INQUIRY AND THE MANAGEMENT \\ OF RESOURCES PUBLIC FINANCIAL
}

\author{
Miguel PÉREZ LÓPEZ
}

RESUMEN: La transición política mexicana iniciada a partir de las elecciones federales de 1997 no contó con un correlativo ajuste total de la Constitución Política de los Estados Unidos Mexicanos, lo que ha acarreado modificaciones parciales a esta ley suprema, a efecto de normar las relaciones entre los actores de poder del sistema político, en particular las tensas relaciones Poder Legislativo-Poder Ejecutivo y las tendencias de hacer efectiva la autonomía constitucional de las entidades federativas frente al poder federal. Por ello - considerando los nuevos escenarios políticos, a fin de contar con la aprobación de las erogaciones plurianuales para proyectos de inversión en infraestructura, fortalecer el aparato institucional de la rendición de cuentas y mejorar el encuadramiento jurídico de la administración de los recursos económicos públicos-, se llevaron a cabo reformas y adiciones a la Constitución federal, publicadas el 7 de mayo de 2008.

Palabras clave: erogaciones plurianuales, control del gasto público, potestad de fiscalización, entidades de fiscalización superior, administración de los recursos públicos federales.
ABSTRACT: The Mexican political transition that began after the federal elections of 1997 did not have a corresponding adjustment of the Constitution of the United States of Mexico, which has led to partial changes to this Supreme Law, in order to regulate relations between the power actors in the political system, including the strained relations between Legislative and Executive and trends promoting the constitutional autonomy of the States versus Federal Power. Therefore, the May 7, 2008, amendments to the Federal Constitution were carry out considering the new political scenario to have the approval of multi-year expenditures for infrastructure investment projects, strengthening of institutional accountability and improving the legal framework for the management of resources public financial.

Descriptors: Multi-year Expenditures, Control of Public Expedenditure, Power of Inquirity, Superior Accouting Office, Management of Resources Public Financial. 
A mi hijo Rafael Antonio, quien me dio una lección en su lucha por la vida, acompañado por su mamá, Luz Elena.

\section{INTRODUCCIÓN}

En la estrategia inicial de la gestión presidencial de Felipe Calderón Hinojosa (2006-2012), se propuso una amplia reforma del entramado jurídico de las finanzas públicas de la Federación, que consistió en una iniciativa de reformas y adiciones a la Constitución Política de los Estados Unidos Mexicanos, así como propuestas de nuevas leyes (las entonces denominadas Ley del Impuesto de la Contribución Empresarial a Tasa Única y la Ley del Impuesto contra la Informalidad) y de modificaciones a un conjunto sumamente extenso de la legislación administrativa en la materia de tributación, presupuesto, contabilidad gubernamental, gasto público y fiscalización (Ley de Coordinación Fiscal, Ley del Impuesto sobre Tenencia o Uso de Vehículos, Ley del Impuesto Especial sobre Producción y Servicios, Ley del Impuesto sobre la Renta, Código Fiscal de la Federación; Ley Federal de Presupuesto y Responsabilidad Hacendaria, Ley Orgánica de la Administración Pública Federal; Ley General de Desarrollo Social, Ley de Adquisiciones, Arrendamientos y Servicios del Sector Público, y Ley de Obras y Servicios Relacionadas con las mismas).

Atendiendo a la naturaleza compleja del procedimiento revisor de la Constitución federal mexicana (artículo 135), resultó evidente que el Congreso de la Unión aprobase anticipadamente el marco legislativo secundario propuesto, ${ }^{1}$ mientras que el proyecto de modificación constitucional continuó su propia secuencia parlamentaria, el cual culminaría con la publicación del "Decreto que reforma, adiciona y deroga diversas disposiciones de la Constitución Política de los Estados Unidos Mexicanos", en el Diario Oficial de la Federación del 7 de mayo de 2008 .

1 Cfr. el Diario Oficial de la Federación del 1o. de octubre de 2007 y 21 de diciembre de 2007, donde aparecen publicados los decretos que contenían las nuevas leyes y las reformas y adiciones a la legislación ya existente. 
El nuevo marco constitucional en materia de gasto público y fiscalización, entronizado en 2008, se da a casi nueve años de la reforma que instauró la Entidad Superior de Fiscalización de la Federación, en lugar de la antigua Contaduría Mayor de Hacienda de la Cámara de Diputados, ${ }^{2}$ pero la reforma objeto de estas notas tiene mayor alcance, pues su proyección normativa va más allá del ámbito federal, al repercutir en las esferas de los estados, los municipios, el Distrito Federal y sus demarcaciones territoriales (delegaciones), a fin de armonizar el régimen de las finanzas públicas, además de fortalecer el conglomerado institucional cuya finalidad es la fiscalización del gasto público y establecer mejores fundamentos para la administración de los recursos económicos públicos.

En el presente trabajo se hará una breve exposición del procedimiento seguido por el órgano revisor de la Constitución, para después comentar, así sea de forma somera, el conjunto de las reformas y adiciones en materia de gasto público y fiscalización.

\section{EL PROCEDIMIENTO DE LA REFORMA}

\section{Las iniciativas}

En realidad, la reforma tuvo un doble origen. En la LIX Legislatura del Congreso de la Unión, la senadora Georgina Trujillo Zentella presentó una iniciativa de reformas a los artículos 74, 79, 110, 111, 116 y 122 constitucionales, en abril de 2004, con el objeto de fortalecer las atribuciones del Poder Legislativo en materia de control y vigilancia de la gestión gubernamental, para lo cual se proponía elevar la calidad, oportunidad y autonomía de las instituciones encargadas de la fiscalización superior.

La propuesta consistía en: a) adelantar la fecha de presentación de la cuenta pública del ejercicio anterior el último día hábil de febrero y reducir el plazo de presentación del informe de resultados a más tardar el 31 de octubre del mismo año de su presentación; b) puntualizar el deber de la Cámara de Diputados de dictaminar la cuenta pública; c) uniformar los sistemas de fiscalización de la Federación, de los estados y del Distrito Federal, desde el máximo nivel normativo del país, y $d$ ) incorporar

2 La reforma constitucional fue publicada en el Diario Oficial de la Federación del 30 de julio de 1999. 
al titular de la Entidad de Fiscalización Superior de la Federación en el conjunto de los servidores públicos dotados de la protección constitucional prevista en el artículo 111 de la ley suprema. ${ }^{3}$

Esta iniciativa fue dictaminada favorablemente y aprobada por el Pleno del Senado, más allá de las dos terceras partes exigidas por el artículo 135 constitucional, enviándose la minuta respectiva a la Cámara de Diputados. ${ }^{4}$

Con posterioridad, el 19 de junio de 2007, el Ejecutivo federal presentaría su iniciativa de reforma constitucional en materia de gasto público y fiscalización ante la Cámara de Diputados, que afectaba los artículos 73, 74, 79 y 134 del Código Político. ${ }^{5}$

Aparte de ser considerada parte troncal de la reforma financiera, la iniciativa tenía como principales objetivos: a) incrementar la calidad del gasto público, mediante la incorporación, en el artículo 134 constitucional, del principio de la obtención de resultados en la programación, administración y ejercicio de los recursos públicos, y del principio normativo de transparencia en dicha administración y ejercicio por parte de los entes públicos de los órdenes federal, local y municipal de la República; b) la constitucionalización indubitable de las erogaciones plurianuales para inversión en infraestructura, inserta como una facultad de la Cámara de Diputados en la autorización de dichas erogaciones, destinadas a proyectos de inversión en infraestructura, consideradas en plazos que rebasen la tradición constitucional de la anualidad presupuestal, con el señalamiento expreso de su inclusión puntual en los subsecuentes presupuestos de egresos de la Federación, y c) el fortalecimiento de la transparencia y la rendición de cuentas, consistente en aprovechar el espacio de la derogada fracción VI del artículo 74 constitucional, ${ }^{6}$ a efecto de reubicar en ella el contenido dedicado a las atribuciones de la

3 La iniciativa aparece en la Gaceta del Senado del 27 de abril de 2004.

4 El dictamen de las Comisiones Unidas de Puntos Constitucionales, de Hacienda y Crédito Público, y de Presupuesto y Cuenta Pública, fue publicado en la Gaceta del Senado del 22 de febrero de 2005.

5 La iniciativa puede verse la Gaceta Parlamentaria de la Cámara de Diputados del 27 de abril de 2004.

6 Dicha fracción preveía la facultad de la Cámara de Diputados para aprobar los nombramientos de magistrados del Tribunal Superior de Justicia del Distrito Federal, formulados por el presidente de la República, misma que fue derogada mediante el decreto publicado en el Diario Oficial de la Federación del 10 de agosto de 1987. 
Cámara de Diputados en materia de la cuenta pública, además de llevar a cabo modificaciones en las fechas de presentación de la cuenta pública ante la Cámara y del informe de resultados a cargo de la Auditoría Superior de la Federación, de fijar de forma patente los principios rectores de la actividad de dicha entidad fiscalizadora (posterioridad, anualidad, legalidad, definitividad e imparcialidad) e incorporar disposiciones de la Ley de Fiscalización Superior de la Federación en el artículo 79 de la Constitución, así como una adición al artículo 73, base de la competencia del Poder Legislativo de la Unión, para que el Congreso expida una ley general en materia de contabilidad gubernamental y de presentación de información financiera, presupuestaria y patrimonial en los ámbitos federal, local y municipal.

\section{El dictamen en la Cámara de Diputados}

Las comisiones encargadas del estudio de la iniciativa del Ejecutivo y de la minuta del Senado, consideraron que era indispensable regular la función gubernamental en el ejercicio de los recursos públicos, a fin de que el gasto público fuese más eficiente, resaltando, como coincidencia entre la minuta enviada por la colegisladora y la iniciativa presidencial, la necesidad de modificar el sistema constitucional en materia de gasto público y fiscalización. En su dictamen, asentaron su coincidencia en lo general con la iniciativa y expresaron cambios a la propuesta del Ejecutivo en el siguiente orden:

a) Incluir a los órganos político-administrativos de las demarcaciones territoriales del Distrito Federal en los nuevos contenidos de la fracción XXVIII del artículo 73 y del artículo 134 de la Constitución general de la República.

b) Fijar en 30 días naturales la duración de la prórroga requerida por el Ejecutivo para la presentación de la cuenta pública, así como establecer el mismo tiempo adicional para la presentación por parte de la Auditoría Superior de la Federación, del informe del resultado de la cuenta pública. En el mismo tenor se propuso la aclaración de que la fecha límite para concluir la revisión de la cuenta pública anual es independiente de los procedimientos relativos a las observaciones, recomendaciones y acciones llevadas a cabo por la Auditoría Superior de la Federación, que seguirían 
su propio desenvolvimiento en los términos marcados por el artículo 79 de la Constitución.

c) Entre los principios rectores de la función fiscalizadora se incluyó el de confiabilidad.

d) Se puntualizó la facultad del ente de fiscalización superior de la Federación para practicar auditorías respecto del desempeño en el cumplimiento de los objetivos contenidos en los programas federales.

e) Las participaciones federales transferidas a los estados de la Unión y a los municipios fueron excluidas de la fiscalización directa del ente de fiscalización superior.

f) Se propuso la fiscalización directa de los recursos federales ejercidos por cualquier entidad, persona física o moral, pública o privada, y los transferidos a fideicomisos, mandatos, fondos o cualquier acto jurídico, a efecto de fincar las responsabilidades que correspondieran.

g) Fue agregado el imperativo de que todas las entidades fiscalizadas deberán llevar el control y registro contable, patrimonial y presupuestario de los recursos de la Federación que les sean transferidos.

h) En cuanto al procedimiento concerniente a la formulación al informe preliminar sobre el resultado de la revisión de la cuenta pública, fue reformulado, en cuanto a la fecha de entrega (a más tardar el 20 de febrero del año siguiente al de la presentación de la cuenta anual); a su presentación al Pleno de la Cámara; el contenido mínimo del informe preliminar; a la vista a las entidades fiscalizadas del contenido del informe a fin de que presenten las justificaciones y aclaraciones que correspondan, para su valoración por parte de la Auditoría Superior de la Federación para la elaboración del informe del resultado de la revisión de la cuenta pública; a la posibilidad de sancionar a las entidades fiscalizadas que incumplan la prevención de desahogo de información, y en cuanto a las recomendaciones al desempeño, las entidades fiscalizadas deberán informar al ente de fiscalización superior sobre las mejoras que se hayan realizado o justificar su improcedencia.

i) Las comisiones sugirieron que la Auditoría Superior de la Federación rindiese un informe sobre la situación que guardaran las observaciones, recomendaciones y acciones promovidas, fijando como fechas de entrega los días 15 de los meses de abril y octubre de cada año.

j) Con la finalidad de fortalecer al ente de fiscalización superior, se propuso la imposición del deber a los entes fiscalizados de proporcionar 
las facilidades necesarias a la Auditoría Superior de la Federación, que ésta requiriera para el ejercicio de sus funciones.

En cuanto al contenido de la minuta remitida por el Senado, las comisiones dictaminadoras consideraron pertinente que se adoptaran las modificaciones propuestas a los artículos 116 y 122 de la ley fundamental, a fin de homologar las funciones de fiscalización y revisión de cuentas públicas de los estados y del Distrito Federal con las de la entidad de fiscalización federal, con lo que se facilitaría a la Auditoría Superior de la Federación la revisión del destino de los recursos federales ejercidos por las entidades federativas. De esta manera, se finca el basamento constitucional común para crear órganos de fiscalización y prescribir desde el Código Político los principios rectores a que deberá sujetarse la función fiscalizadora, con miras de alcanzar la armonización entre las entidades federal y locales, procurando el respeto de la autonomía de los estados y el Distrito Federal, en lo concerniente a las características de dichos órganos y de los procedimientos que asuman.

Como consecuencia de la reforma a las bases constitucionales de las entidades federativas (artículos 116 y 122), las comisiones reformularon la propuesta presidencial respecto al artículo 134 de la Ley Suprema de la Unión, para extender su ámbito de aplicación a las entidades federativas, los municipios y los órganos político-administrativos de las demarcaciones territoriales del Distrito Federal (las también llamadas "delegaciones", como las denomina el Estatuto de Gobierno de la capital).

El dictamen fue discutido en la sesión plenaria del 13 de septiembre de 2008, en la que el diputado Alberto Amador Leal hizo una reserva del artículo 79, la que finalmente no fue atendida. La Cámara aprobó la reforma en general por 463 votos, ninguno en contra y dos abstenciones. Una vez que el dictamen fue aprobado por el Pleno de la Cámara de Diputados se remitió la correspondiente minuta al Senado de la República.

\section{El dictamen del Senado}

La minuta fue turnada a las Comisiones Unidas de Puntos Constitucionales; de Hacienda y Crédito Público y de Estudios Legislativos, las que emitieron su correspondiente dictamen el 13 de septiembre de $2007 .^{7}$

7 El dictamen apareció en la Gaceta del Senado del 18 de septiembre de 2007. 
El dictamen sintetiza el contenido de la minuta con proyecto de decreto remitida por la colegisladora y expone asentimiento con lo incorporado y aprobado en la minuta.

En la discusión del Pleno de la Cámara de Senadores, en su sesión del 18 de septiembre de 2007, el senador Ricardo Monreal, entonces perteneciente a la bancada del Partido de la Revolución Democrática, propuso una reserva respecto del contenido de los párrafos primero, segundo y tercero del artículo 79 constitucional, argumentando que con la reforma se trataba de superar las reticencias de siete estados de la Unión para celebrar convenios con la Auditoría Superior de la Federación, con demérito de la autonomía de los estados y del pacto federal.

En tal virtud, se procedió a dividir la votación. Por lo que hace a los artículos no reservados, fueron aprobados por unanimidad de 118 votos, superando con mucho el requisito constitucional de la votación calificada. En cuanto a los párrafos reservados, el senador Monreal no formuló cambios sino expresó que se abstendría de votar, por lo que al captarse la votación se obtuvieron 101 votos a favor, ninguno en contra y 13 abstenciones.

Pasemos a analizar los temas compendiados en la que era una impostergable enmienda constitucional, cuyo principal telos era reforzar, en parte, el régimen presupuestal y el andamiaje del sistema de fiscalización, a fin de que los recursos económicos públicos fueran debidamente aprovechados, no nada más los de la Federación sino también los de las entidades federativas, los municipios y las demarcaciones territoriales del Distrito Federal.

\section{UNA POTESTAD LEGISLATIVA INÉDITA EN EL SISTEMA FEDERAL MEXICANO}

Contrario a una tradición constitucional de mantener incólumes las fracciones o incisos de los preceptos de la ley suprema de la Unión que hubiesen sido derogadas, el órgano revisor decidió aprovechar el espacio de la derogada fracción XXVIII del artículo $73,{ }^{8}$ a fin de dotar al Con-

8 La nueva fracción XXVIII corresponde a una materia distinta a la que anteriormente contenía dicho precepto: la atribución del Congreso de la Unión para constituirse en Colegio Electoral y elegir al ciudadano que debería sustituir al presidente de la República, con el carácter de sustituto o provisional, en los término de los artículos 84 y 
greso de la Unión de una facultad nueva en el abigarrado esquema de distribución de competencias del sistema federal entre sus componentes (Federación, estados, Distrito Federal y municipios), que se distingue respecto de las facultades expresas, implícitas, coincidentes, concurrentes, de auxilio federal a los estados, de colaboración y de jurisdicción dual.

En la nueva fracción XXVIII del artículo 73 constitucional, el Congreso de la Unión fue dotado de la potestad para expedir leyes en materia de contabilidad gubernamental, que regirán la contabilidad pública y la presentación homogénea de información financiera, de ingresos y egresos, así como patrimonial, tanto para la Federación, los estados, los municipios, el Distrito Federal como sus órganos político-administrativos de sus demarcaciones territoriales, con el fin de garantizar su armonización a nivel nacional.

Esta novedosa potestad legislativa del Congreso de la Unión propicia un campo de poca exploración en el derecho constitucional mexicano.

Han existido algunas reflexiones sobre la existencia de facultades constitucionales de tipo nacional, que estén por encima de los entes públicos de la Federación y les impongan atribuciones, funciones y finalidades. En primer lugar, tendríamos las propuestas de Ulises Schmill Ordóñez, quien considera que en este orden de carácter nacional (lo denomina "orden total o del Estado federal", apoyándose en la doctrina kelseniana) se encontraban la función de reforma y adición constitucional, la reforma de la Constitución (en su aspecto geográfico), la suspensión de garantías y los medios de defensa de la Constitución. ${ }^{9}$

A su vez, Jorge Carpizo ha considerado que la categoría "nacional" era aplicable a la Universidad Nacional Autónoma de México y a la Comisión Nacional de los Derechos Humanos para conocer de las inconformidades formuladas en relación con las recomendaciones, acuerdos y omisiones de los órganos protectores de los derechos humanos de las entidades federativas (artículo 102, apartado "B", último párrafo).

Esta facultad legislativa de alcances nacionales se asemeja a la facultad concurrente; sin embargo, es evidente su diferencia radical. En

85 constitucionales, misma que fue derogada mediante el decreto publicado en el Diario Oficial de la Federación del 6 de diciembre de 1977.

9 Schmill Ordóñez, Ulises, El sistema de la Constitución mexicana, 2a. ed., México, Textos Universitarios, 1977, pp. 141 y 142. 
la facultad concurrente, como la ha establecido la Constitución federal mexicana, ${ }^{10}$ la ley fundamental otorga al Congreso de la Unión el poder para expedir leyes (calificadas redundantemente de "generales"), mediante las cuales se reparten competencias, sobre una misma materia, entre la Federación, los estados, el Distrito Federal y los municipios. Dichas competencias pueden ser desarrolladas en detalle por los órganos legislativos locales (legislaturas locales y la Asamblea Legislativa de la capital del país), sobre los aspectos predeterminados en la "ley general". El haz de materias que abarcan las facultades concurrentes ha ido creciendo de forma constante (educación, salud, protección civil, asentamientos humanos, protección al medio ambiente, seguridad pública, deporte, turismo, pesca, sociedades cooperativas), lo que marca una tendencia del federalismo mexicano en las últimas cuatro décadas.

En cambio, la facultad legislativa de alcances nacionales, en los términos del nuevo contenido de la fracción XXVIII del artículo 73, monopoliza en el Poder Legislativo federal la creación del marco jurídico al que deberán sujetarse las entidades federativas. De ninguna manera se trata de una facultad federal exclusiva, sustentada en la dicotomía de competencias del artículo 124 constitucional, por la que se determina que las facultades no otorgadas a la Federación, se entienden reservadas a los estados.

Estamos ante una potestad asignada al Poder Legislativo de la Unión que se coloca por encima de todas las autoridades del sistema federal mexicano, con miras de garantizar la armonía en materia de contabilidad gubernamental.

De la potestad legislativa nacional contenida en la fracción 73 del código político se aprecian las siguientes características:

10 En la doctrina constitucional mexicana dominó durante un buen tiempo la crítica de Felipe Tena Ramírez respecto al empleo en la Constitución del término "facultades concurrentes", para la potestad del Poder Legislativo federal de distribuir atribuciones, inicialmente, entre la Federación y los estados, agregándose con posterioridad al Distrito Federal y a los municipios, puesto que se contrariaba el sentido que dicho término tenía en la doctrina estadounidense. Sin embargo, la práctica del órgano revisor de la Constitución mexicana ha mantenido su propio curso, a pesar de la crítica del distinguido constitucionalista michoacano. Cfr. Arteaga Nava, Elisur, Derecho constitucional, México, Oxford, 2008; Tena Ramírez, Felipe, Derecho constitucional mexicano, 29a. ed., México, Porrúa, 1995, pp. 112-123. 
a) Se instituye la materia de contabilidad gubernamental, que comprende la contabilidad pública y la presentación homogénea de información financiera, de ingresos, egresos y patrimonial.

b) El ámbito orgánico de aplicación de la nueva disposición fundamental comprende a la Federación, los estados, el Distrito Federal, los municipios y los órganos político-administrativos de las demarcaciones territoriales o delegaciones de la capital del país.

c) El marco jurídico secundario que derivará de la potestad legislativa nacional impondrá un régimen jurídico ineludible para los componentes del sistema federal mexicano, lo que se refuerza con el aumento de las atribuciones de la Entidad de Fiscalización Superior de la Federación, la elevación constitucional de las bases en que deberán apoyarse los sistemas de fiscalización de los estados y del Distrito Federal, y las reformas y adiciones al artículo 134 constitucional, que también son objeto del decreto publicado el 7 de mayo de 2008.

d) La amplitud de la facultad de alcance nacional es una medida extrema, motivada por las renuencias a ser fiscalizados de parte de algunas entidades federativas, como se expuso en el dictamen de la Cámara de Diputados, rendido en el procedimiento de reforma que nos ocupa, así como en el debate en el Senado de la República. Una de las secuelas políticas del proceso electoral de 2000, fue la desvinculación y distanciamiento de los poderes locales, en especial los gobernadores, respecto de la Federación. Rotos los vínculos metaconstitucionales entre la Federación y los gobiernos de los estados y, un poco menos, con el Distrito Federal, era necesario crear un marco constitucional mediante el cual fuera posible el control financiero en el sistema federal mexicano. ${ }^{11}$

e) Respecto de esta facultad legislativa de alcances nacionales, que incide en el ordenamiento mexicano, el decreto que la adiciona a la Constitución federal, instituye en su transitorio segundo que el Congreso de la Unión, las legislaturas de los estados y la Asamblea Legislativa del Distrito Federal, deberán aprobar las leyes y, en su caso, las reformas que sean necesarias a fin de cumplir con las nuevas previsiones constitucionales a más tardar en un plazo de un año, contado a partir de la entrada

11 Loewenstein, Karl, Teoría de la Constitución, Barcelona, Ariel, 1976, pp. 54-72; Valadés, Diego, El control del poder, 2a. ed., México, Porrúa-UNAM, 2000, pp. 95-101 y 188-191. Cfr. Pedroza de la Llave, Susana Thalía, El Congreso general mexicano. Análisis sobre su evolución y funcionamiento actual, México, Porrúa, 2003, pp. 295-303. 
en vigor del decreto. En lo que hace a la restaurada fracción XXVIII del artículo 73, el Congreso federal expidió la Ley General de Contabilidad Gubernamental, asimismo derogó las disposiciones relativas a la contabilidad gubernamental de la Ley Federal de Presupuesto y Responsabilidad Hacendaria. ${ }^{12}$

\section{REDEFINICIÓN DE LAS FACULTADES FINANCIERAS DE LA CÁMARA DE DiPUTADOS}

La reforma constitucional de mayo de 2008 incidió en el ámbito competencial de la Cámara de Diputados, en cuanto a distinguir sus facultades de fiscalización en el conjunto del artículo 74 de la ley suprema de la Unión.

De la fracción IV del artículo 74, fueron retiradas las referencias a la facultad de revisión de la cuenta pública, pero se restauró la hasta entonces derogada fracción VI, con el fin de que en ésta quedara asentada dicha facultad. ${ }^{13}$ En la fracción IV se reformaron los párrafos primero y octavo, aunque se derogaron sus párrafos quinto, sexto y séptimo.

\section{Incorporación de las erogaciones plurianuales}

En el primer párrafo de la fracción IV del artículo 74, quedó asentada la posibilidad de que en el Presupuesto de Egresos de la Federación se podrían autorizar las erogaciones plurianuales para los proyectos de inversión en infraestructura que se determinaran en la ley reglamentaria, con el imperativo de que las erogaciones correspondientes deberían consignarse en los subsecuentes presupuestos de egresos.

La reforma parte de una realidad política-electoral: en virtud de que, desde 1997, se dio un cambio en la composición política de la Cámara de Diputados, que ha provocado tensiones entre las fracciones parlamentarias, así como entre la Cámara y el presidente de la República. En la conformación del sistema político anterior a 1997, el Ejecutivo no encontró

12 Diario Oficial de la Federación del 31 de diciembre de 2008.

13 Dicha fracción VI establecía la facultad de la Cámara de Diputados de aprobar los nombramientos de los magistrados del Tribunal Superior de Justicia del Distrito Federal. La derogación apareció en el decreto publicado en el Diario Oficial de la Federación del 10 de agosto de 1987. 
problema sustancial de parte de la Cámara en el momento de aprobarse el Presupuesto de Egresos y la cuenta pública anual, por lo que el financiamiento de los proyectos de infraestructura no representaba un problema político, ni económico. Si acaso existía una limitante política: la duración sexenal de la gestión presidencial, que además, desde la presidencia de Lázaro Cárdenas (1934-1940), estaba empatada con la duración constitucional de las cámaras del Congreso de la Unión.

Ante la tendencia política de los últimos años, en la que el electorado vota de forma dividida, se ha considerado conveniente que se plantee la posibilidad de la incorporación de las erogaciones plurianuales, que no queden sujetas a los vaivenes de la composición de la Cámara, por un cambio de legislatura, sobre todo a mitad de un sexenio presidencial.

La reforma plantea que la ley reglamentaria defina las características que deben reunir los proyectos de inversión en infraestructura que rebasen un año fiscal, a fin de que el Ejecutivo quede limitado a los parámetros legales en la formulación de los proyectos. La ley reglamentaria sería, en este momento, la Federal de Presupuesto y Responsabilidad Hacendaria.

Se reformó el entonces octavo párrafo de la fracción IV, sólo para purgar la referencia a la cuenta pública en lo que toca a la solicitud de ampliación del plazo de presentación de la iniciativa de la Ley de Ingresos y del Presupuesto de Egresos. Al ser derogados los párrafos quinto, sexto y séptimo de la fracción IV, ahora el octavo queda realmente como párrafo quinto.

\section{La potestad de revisión de la cuenta pública}

La restaurada fracción VI del artículo 74 cimentó la facultad de la Cámara para revisar la cuenta pública, desglosándose de la siguiente forma:

a) Mientras en la anterior fracción IV, se preveía que el objeto de la revisión de la cuenta pública consistía en conocer los resultados de la gestión financiera, comprobar si se había ajustado a los criterios señalados por el Presupuesto y el cumplimiento de los objetivos contenidos en los programas, en la nueva fracción VI se redefine el objeto de la revisión: la representación nacional evaluará los resultados de la gestión financiera y verificará el cumplimiento de los objetivos de los programas. 
b) La fracción VI mantiene la previsión constitucional de que la potestad revisora de la cuenta pública asignada a la Cámara de Diputados se llevará a través de la entidad de fiscalización superior federal, agregándose que en el caso de revisión sobre el cumplimiento de los objetivos de los programas, la entidad de fiscalización superior sólo podrá emitir las recomendaciones para la mejora en el desempeño de los mismos, en los términos de la ley.

c) En el tercer párrafo de la nueva fracción VI se reduce la fecha para la presentación de la cuenta pública: de su depósito en los primeros diez días de junio (durante el receso de sesiones del Congreso) se pasó a la fecha límite del 30 de abril del año siguiente al ejercicio presupuestal por revisar. Se mantiene la posibilidad de ampliar el plazo de presentación, con la nueva limitante de que la prórroga no deberá exceder 30 días naturales y, como consecuencia, la Entidad de Fiscalización Superior de la Federación contará con el mismo tiempo adicional para la presentación del informe del resultado de la revisión de la cuenta pública.

d) Es novedoso, a nivel constitucional, el límite temporal para que la Cámara concluya la revisión de la cuenta pública: se fija como fecha al 30 de septiembre del año siguiente al de su presentación. Además, se prescribe que la revisión de la cuenta pública se lleve a cabo con base en el análisis de su contenido y de las conclusiones técnicas del informe del resultado que emita la Entidad de Fiscalización Superior, sin menoscabo de que el trámite de las observaciones, recomendaciones y acciones promovidas por dicha entidad, seguirá su curso en los términos del artículo 79 constitucional.

e) El último párrafo de la restaurada fracción VI del artículo 74, instituye que la Cámara de Diputados ejercerá una facultad de control sobre la Auditoría Superior de la Federación: evaluará su desempeño y le podrá requerir informes sobre la evolución de sus trabajos de fiscalización.

f) De acuerdo con la entrada en vigor del nuevo estatuto constitucional sobre la presentación de la cuenta pública y el informe del resultado sobre su revisión, el artículo tercero transitorio prevé que las fechas aplicables entrarán en vigor a partir de la cuenta pública correspondiente al ejercicio fiscal 2008.

g) Finalmente, el transitorio cuarto del decreto de reformas y adiciones despliega las fechas para el ejercicio de la facultad revisora de la Cámara de Diputados sobre las cuentas públicas anteriores al ejercicio fiscal 2008. 


\section{EL FORTALECIMIENTO DE LA FISCALIZACIÓN SUPERIOR DE LA FEDERACIÓN: PRINCIPIOS CONSTITUCIONALES, NUEVOS PLAZOS, INCREMENTO COMPETENCIAL, MEDIOS DE IMPUGNACIÓN Y DEBERES DE APOYO}

A LA FUNCIÓN FISCALIZADORA

Formalmente resultó compleja la modificación del artículo 79 constitucional, basamento de la función fiscalizadora. Fueron reformadas las fracciones I y II, y el que era el párrafo quinto; además, fue adicionado un párrafo segundo, lo que motivó el recorrido de los que eran los párrafos segundo a sexto para quedar como tercero a séptimo párrafos.

En cuanto a su contenido, se aprecian los siguientes cambios:

\section{Principios constitucionales}

El nuevo párrafo segundo del artículo 79 prevé que la función de fiscalización se ejercerá conforme a los principios de posterioridad, anualidad, legalidad, definitividad, imparcialidad y confiabilidad. Los cinco primeros provienen de la iniciativa del Ejecutivo federal de junio de 2007 y el último lo agregaron las comisiones dictaminadoras de la Cámara de Diputados.

El principio de posterioridad significa que la Auditoría Superior de la Federación cumplirá con sus atribuciones de fiscalización una vez que ha transcurrido el ejercicio fiscal que será objeto de su función, además de quedar sujeta a la causa eficiente de la misma, que viene a ser la presentación de la cuenta pública que envíe el presidente de la República.

El principio de anualidad obliga a que la función fiscalizadora debe ajustarse al año fiscal (en México coincide con el año calendario) durante el cual se ejerce el presupuesto, sin demérito, como se apreciará más adelante, que la función rebase el año fiscal, cuando se trate de la revisión de las erogaciones plurianuales para inversión en infraestructura.

Por tratarse de un órgano del Estado, la actividad fiscalizadora de la Auditoría Superior de la Federación debe quedar ajustada a las prescripciones del ordenamiento jurídico, con el objeto de proporcionar un perímetro y cimiento de legalidad a sus actuaciones.

Ligado con el principio de legalidad, tenemos que la función fiscalizadora debe ser completa, eficiente y exhaustiva, a fin de evitar expedientes 
abiertos, que puedan propiciar conflictos políticos y jurídicos intermitentes, por lo que las decisiones que asuma la Entidad de Fiscalización Superior sean definitivas, sin que el principio de definitividad sea óbice para que la Auditoría Superior emita las sanciones y formule las denuncias que correspondan.

Si bien es cierto que el principio de imparcialidad resulta común en el entramado constitucional (al menos en los artículos 6o., fracción IV, 13, 17 y 113), su inclusión como uno de los rectores de la función fiscalizadora responde a que la Auditoría Superior de la Federación, por su naturaleza de órgano técnico, tiene vedado que su actuación y resoluciones tengan sesgos político-partidistas.

Corolario de lo anterior, el principio de confiabilidad implica que el ejercicio de la función fiscalizadora se ajuste a la técnica, metodología, procedimientos y operaciones de comprobación, sin asomo de un ánimo de persecución política, siempre flotante en la clase política mexicana. A la función fiscalizadora, también le es extensible el conjunto de principios y bases constitutivos del derecho de acceso a la información, previsto en el segundo párrafo del artículo 6o. de la Constitución federal.

\section{Nuevos plazos constitucionales}

La reforma que nos ocupa replantea las fechas y plazos en materia de fiscalización. En primer lugar, el ahora derogado párrafo séptimo de la fracción IV del artículo 74 constitucional prescribía que la cuenta pública del año anterior debería ser presentada a la Cámara de Diputados, dentro de los diez primeros días de junio. En la rehabilitada fracción VI, segundo párrafo del artículo 74 de la ley suprema, se acorta el plazo para señalar como fecha al 30 de abril del año siguiente.

Es mantenida la posibilidad de ampliar el plazo de presentación de la cuenta pública en el tercer párrafo de la fracción VI, extrapolando el contenido del último párrafo de la fracción IV, en lo que se refiere al requisito de procedibilidad de la solicitud de ampliación, que deberá ser suscrita por el presidente de la República, y encontrarse suficientemente justificada a juicio de la Cámara o de la Comisión Permanente, y con el imperativo de la comparecencia, se entiende que indistintamente ante la Cámara o la Permanente, secretario del despacho correspondiente a informar las razones de la solicitud. La ampliación no debe superar el plazo 
de 30 días naturales y se entenderá que la Auditoría Superior de la Federación contará con el mismo tiempo adicional para presentar el informe del resultado de la revisión de la cuenta pública. En segundo término, se reformó la fracción II del artículo 79 constitucional, para señalar nueva fecha en que la entidad de fiscalización superior entregue el informe del resultado de revisión a la Cámara de Diputados: se acorta la fecha del 31 de marzo del año siguiente al de la presentación de la cuenta pública, se pasa ahora al 20 de febrero de dicho año. Además, dicha entidad tiene el deber de entregar a la Cámara de Diputados los días primeros de mayo y noviembre de cada año, un informe sobre la situación que guardan las observaciones, recomendaciones y acciones promovidas.

Por último, la nueva fracción VI del artículo 74 fija el 30 de septiembre del año siguiente al de su presentación, como la fecha para que la Cámara de Diputados concluya la revisión de la cuenta pública, sin menoscabo de que el trámite de las observaciones, recomendaciones y acciones promovidas por la Auditoría Superior de la Federación, sigan su curso, lo que resalta la autonomía técnica y de gestión en el ejercicio de sus atribuciones. ${ }^{14}$

\section{Incremento competencial}

En realidad, la reforma constitucional de mayo de 2008 elevó al máximo rango normativo, atribuciones de la Auditoría Superior de la Federación que la ley reglamentaria le concedía. A fin de superar argumentos de posibles transgresiones a la ley fundamental (en particular, hipotéticas invasiones de esferas de competencias), el órgano revisor de la Constitución consideró necesario consolidar la potestad de la Entidad de Fiscalización Superior de la Federación.

De esta forma, las reformas y adiciones constitucionales en materia de fiscalización procuran abatir reticencias, elevan al máximo nivel norma-

14 El transitorio tercero del "Decreto que reforma, adiciona y deroga diversas disposiciones de la Constitución Política de los Estados Unidos Mexicanos", en el Diario Oficial de la Federación del 7 de mayo de 2008, estableció que las nuevas fechas para la presentación de la cuenta pública y el informe del resultado sobre su revisión, entrarían en vigor a partir de la cuenta pública correspondiente al ejercicio fiscal 2008. Resulta lógico que dicha disposición transitoria también sea aplicable a la fecha de término para la facultad de la Cámara de concluir la revisión de la cuenta pública de 2008. 
tivo y refuerzan la institución encargada de apoyar a la Cámara de Diputados en la revisión de la cuenta pública.

Las atribuciones de la Entidad de la Fiscalización Superior de la Federación incorporadas o redefinidas en el artículo 79 de la ley suprema son las siguientes:

a) La entidad realizará auditorías sobre el desempeño en el cumplimiento de los objetivos contenidos en los programas federales (párrafo inicial de la fracción I).

b) El segundo párrafo extiende la potestad fiscalizadora de la Auditoría Superior de la Federación. Además de fiscalizar directamente los recursos federales, con excepción de las participaciones federales, que administren o ejerzan los estados, municipios y el Distrito Federal, la reforma extiende la función fiscalizadora a los órganos político-administrativos de las demarcaciones de la capital del país. Mientras en la reforma constitucional de $1999,{ }^{15}$ se previó que la función fiscalizadora alcanzaría a "los particulares". La compendiosa definición fue extendida con la reforma de 2008: la Auditoría Superior podrá fiscalizar el uso de los recursos federales destinados y ejercidos por cualquier entidad, persona física o moral, pública o privada, "y los transferidos a fideicomisos, mandatos, fondos o cualquier otra figura jurídica, de conformidad con los procedimientos establecidos en las leyes y sin perjuicio de la competencia de otras autoridades y de los derechos de los usuarios del sistema financiero". Correlativo a esta facultad reformulada, es la obligación constitucional a todas las entidades fiscalizadas de establecer el control y registro contable, patrimonial y presupuestario de recursos federales que les sean transferidos y asignados, conforme a los criterios previstos en la ley, de forma concordante con la facultad del Congreso de la Unión incorporada en la fracción XXVIII del artículo 73 constitucional que, como se vio, fue parte del mismo decreto de reformas y adiciones constitucionales de mayo de 2008.

c) El cuarto párrafo de la fracción I contiene un amplio poder a la Auditoría Superior de la Federación para solicitar y revisar, de manera casuística y concreta, información de ejercicios anteriores al de la cuenta pública en revisión. El precepto en cuestión, sin perjuicio del principio de anualidad, además del de definitividad, de ninguna forma significa

15 Diario Oficial de la Federación del 30 de julio de 1999. 
que es abierta nuevamente la cuenta pública del ejercicio donde se encuentra la información solicitada, pues:

1. Ésta se vincula con un programa, proyecto o erogación, insertos en un presupuesto que abarque diversos ejercicios fiscales para su ejecución y pago, o

2. Cuando se trate de revisiones sobre el cumplimiento de los objetivos de los programas federales. A fin de que los principios de posterioridad, anualidad, definitividad y confiabilidad, sean honrados por la entidad de fiscalización superior, además de respetar las decisiones de la Cámara sobre la revisión de cuentas públicas pretéritas, la parte final del nuevo párrafo cuarto prevé que sus observaciones y recomendaciones únicamente podrán referirse al ejercicio de los recursos públicos de la cuenta pública sometida a su revisión.

d) El último párrafo de la fracción I fue reformado, a fin de precisar un supuesto extraordinario incorporado en la reforma de 1999. Se trata de la facultad de la Auditoría Superior de la Federación de requerir, en las situaciones excepcionales previstas por la ley, a las entidades fiscalizadas que procedan a la revisión de conceptos y le rindan un informe. Las modificaciones incorporadas mediante la reforma de 2008 son las siguientes:

1. La facultad de requerimiento se ejercerá, sin perjuicio del principio de posterioridad, durante el ejercicio fiscal en curso, y

2. A partir de la formulación de denuncias. Del ejercicio de dicha facultad, la Entidad de Fiscalización Superior de la Federación deberá rendir un informe específico a la Cámara de Diputados y, de forma novedosa, fincará las responsabilidades correspondientes (que serán de tipo resarcitorio, en los términos de la fracción IV del mismo artículo 79 constitucional) o promoverá otras responsabilidades ante las autoridades competentes (que pueden ser de orden penal o administrativo). Es mantenida la posibilidad de fijar legalmente sanciones, en caso de desacatar los requerimientos de la entidad, en los plazos y formas previstas en la ley reglamentaria. 
e) Conforme a una tendencia dominante a las formas practicadas por el órgano revisor de la Constitución de aumentar los párrafos de los textos del código político, una especie de "gigantismo" constitucional, en esta modificación que analizamos, la fracción II del artículo 79 pasó de dos a siete párrafos. En el primer párrafo, dedicado al imperativo a la $\mathrm{Au}-$ ditoría Superior de la Federación de la entrega del informe del resultado de la revisión de la cuenta pública a la Cámara de Diputados, se resalta el carácter público del informe y se puntualiza su contenido, el cual deberá prever:

1. Las auditorías practicadas;

2. Los dictámenes de su revisión;

3. Los apartados correspondientes a la fiscalización del manejo de recursos federales por los estados, los municipios, el Distrito Federal y los órganos político-administrativos de sus delegaciones, y las personas físicas o morales, públicas o privadas;

4. Los apartados dedicados a la verificación del desempeño en el cumplimiento de los objetivos de los programas federales, y

5. Un apartado específico con las observaciones de la Entidad de Fiscalización Superior, que contenga las justificaciones y aclaraciones que, en su caso, formulen las entidades fiscalizadas respecto de dichas observaciones.

f) El segundo párrafo de la fracción II del artículo 79 eleva, a rango constitucional, la oportunidad de defensa de las entidades fiscalizadas, para que expongan las justificaciones y aclaraciones respecto de la parte de los resultados de la revisión que les corresponda, de forma previa a la presentación del informe del resultado. El nuevo precepto constitucional obliga a la Auditoría Superior de la Federación, a valorar las justificaciones y aclaraciones formuladas por las entidades fiscalizadas al momento de elaborar el informe del resultado de la revisión de la cuenta pública.

g) Los párrafos quinto, sexto y séptimo de la fracción II del artículo 79 regulan las recomendaciones y acciones que emita el titular de la Entidad de Fiscalización Superior de la Federación, quien las remitirá a las entidades fiscalizadas, dentro de un plazo de diez días hábiles siguientes a la entrega del informe del resultado a la Cámara de Diputados. Las entidades fiscalizadas contarán con un plazo de hasta 30 días hábiles para que exhiban la información y realicen las consideraciones que estimen perti- 
nentes, pues en caso de omisión se aplicarán las sanciones que prevea la ley. Se establece la salvedad de que dichas previsiones son inaplicables a los pliegos de observaciones y a las promociones de responsabilidad, pues la ley secundaria regulará los procedimientos y términos para dichas cuestiones.

h) El quinto párrafo adicionado a la fracción II del artículo 79, le impone a la Auditoría Superior de la Federación un plazo de 120 días hábiles sobre las respuestas que formulen las entidades fiscalizadas. De no contestar, se presumirá que se tendrán por atendidas las recomendaciones y acciones de parte de las entidades.

i) Cuando se trate del caso de recomendaciones al desempeño, las entidades fiscalizadas deberán precisar ante la Entidad de Fiscalización Superior de la Federación cómo fueron llevadas a cabo las mejoras o justificar la improcedencia de éstas.

j) Como ya fue expuesto en este estudio, la Constitución federal obliga a la Auditoría Superior de la Federación a rendir un informe sobre el estado que guardan las observaciones, recomendaciones y acciones promovidas, en el inicio de mayo y noviembre de cada año.

k) El último párrafo de la fracción II del artículo 79, anterior a la reforma constitucional de 2008, establecía la obligación de la Entidad de Fiscalización Superior de la Federación de guardar reserva de sus actuaciones y observaciones hasta que rindiese los informes a que se refería el artículo 79. Ahora el séptimo y último párrafo de la fracción II redefine el término hasta el cual permanecerá dicha obligación de guardar reserva: será hasta que la Auditoría Superior de la Federación rinda el informe del resultado a la Cámara de Diputados.

\section{Medios de impugnación: fiscalización y justicia administrativa}

Mediante el decreto publicado el 7 de mayo de 2008, se adicionaban un párrafo segundo al artículo 79 constitucional y un párrafo segundo a su fracción IV, que más bien pareciera que sería el párrafo cuarto del artículo en cuestión. Lo trascendente es el contenido mismo del nuevo precepto.

La adición en cuestión consiste en elevar a nivel constitucional el contenido del artículo 59 de la entonces vigente Ley de Fiscalización Superior de la Federación, en el cual se establecía que los servidores públicos 
o por los particulares, personas físicas o morales, afectados por las sanciones impuestas y las resoluciones de la Auditoría Superior de la Federación, con fundamento en dicha Ley, podrían impugnarlas mediante el recurso de reconsideración ante la misma entidad o a través del juicio ante el Tribunal Federal de Justicia Fiscal y Administrativa. ${ }^{16}$

La nueva previsión constitucional mantiene el contenido de la disposición legal: la posibilidad de que las entidades fiscalizadas y, en su caso, los servidores públicos afectados que estén adscritos a las entidades, puedan impugnar las sanciones y demás resoluciones de la Entidad Superior de Fiscalización de la Federación ante dicho órgano o ante "los tribunales a que se refiere el artículo 73, fracción XXIX-H de esta Constitución", o sea el Tribunal Federal de Justicia Fiscal y Administrativa.

Esta adición supera una aparente inconstitucionalidad y establece una excepción al principio de separación de poderes. La aparente inconstitucionalidad consistía en que el Tribunal Federal de Justicia Fiscal y Administrativa conocía de la impugnación contra los actos administrativos de un órgano auxiliar del Poder Legislativo de la Federación.

La fracción XXIX-H del artículo 73 constitucional, en inicio, plantea la competencia de dicho Tribunal para dirimir las controversias entre la administración pública federal y los particulares, además de que por virtud de la reforma constitucional de 2006, ahora también tiene competencia para imponer sanciones a los servidores públicos con motivo de responsabilidad administrativa. ${ }^{17}$

Como se aprecia, la competencia material del Tribunal Federal de Justicia Fiscal y Administrativa está dirigida a las controversias donde estuviesen involucradas dependencias y entidades de la administración pública federal, órganos de apoyo de la función, atribuciones y finalidades del Poder Ejecutivo de la Unión, constituyéndose en el contencioso administrativo o la jurisdicción administrativa, ${ }^{18}$ por lo que el tribunal administrativo federal, de acuerdo a lo previsto en el entonces vigente artículo 59 de la Ley de Fiscalización Superior de la Federación, invadía el

16 Esta Ley fue abrogada por el decreto que expide la Ley de Fiscalización y Rendición de Cuentas de la Federación. En este último ordenamiento, se mantiene el mismo sistema de impugnación de los actos de la Auditoría Superior de la Federación, en los artículos 69 a 72 .

17 Diario Oficial de la Federación del 4 de diciembre de 2006.

18 Cfr. Fix-Zamudio, Héctor, Introducción a la justicia administrativa en el ordenamiento mexicano, México, El Colegio Nacional, 1983, pp. 53-60. 
ámbito del Poder Legislativo sin tener apoyo expreso en la ley suprema. De ahí la abstracta inconstitucionalidad del mencionado artículo 59, al contener la invasión de un tribunal administrativo para controlar actos de naturaleza administrativa de un órgano técnico de la Cámara de Diputados. La abstracta y aparente inconstitucionalidad de la entonces vigente Ley de Fiscalización Superior de la Federación quedó rebasada con la nueva disposición agregada después de la fracción IV del artículo 79 de la ley fundamental.

Al mismo tiempo, se autoriza un supuesto de excepción al principio de separación de poderes por el que los actos materialmente administrativos de un órgano técnico, de apoyo a la funciones del Poder Legislativo, en específico la Cámara de Diputados, pueden ser sometidos al conocimiento del tribunal de lo contencioso administrativo federal. ${ }^{19}$

En la elevación constitucional de los medios de defensa es indubitable su carácter optativo, a elección de los inconformes, lo que mantiene una sana tendencia a favor de la opción en la interposición de los medios de defensa en materia administrativa, en lugar de la obligatoriedad. ${ }^{20}$ Igualmente, de dicha previsión fundamental es posible desprender la hipótesis de que no sólo se impugnen resoluciones de la Entidad de Fiscalización Superior de la Federación de efectos particulares y concretos, sino también disposiciones administrativas de carácter general, diversos a los reglamentos, que este órgano llegase a emitir y causen un agravio en la esfera jurídica de los servidores públicos o por los particulares, personas físicas o morales, a que hace referencia el párrafo añadido al artículo 79 constitucional, cuando dichas disposiciones de carácter general sean autoaplicativos o cuando el interesado los controvierta con motivo de su primer acto de aplicación. ${ }^{21}$ De igual forma, se surte la competencia del

19 Fraga, Gabino, Derecho administrativo, 28a. ed., México, Porrúa, 1989, p. 66.

20 Fix-Zamudio, Héctor, op. cit., nota 18, pp. 48-51; González Pérez, Jesús, "La revisión de los actos de la administración pública en vía administrativa", Revista de Estudios de Derecho Público, núm. 1, invierno de 2001, pp. 179-203; Pérez López, Miguel, "El recurso de revisión en la Ley Federal de Procedimiento Administrativo", Revista de Investigaciones Jurídicas, México, núm. 24, 2000, pp. 401 y 402; y Vázquez Alfaro, José Luis, El control de la administración pública en México, México, Instituto de Investigaciones Jurídicas, UNAM, 1996, pp. 61-88.

21 Esta hipótesis de procedencia del juicio contra actos administrativo de carácter general ante el Tribunal Federal de Justicia Fiscal y Administrativa se encuentra prevista en los artículos 2o. de la Ley Federal de Procedimiento Contencioso Administrativo (Diario 
contencioso administrativo federal tratándose de la negativa ficta configurada ante el silencio de la Auditoría Superior de la Federación, de acuerdo con la fracción XIV del artículo 14 de la Ley Orgánica del Tribunal Federal de Justicia Fiscal y Administrativa.

\section{La colaboración de la entidades fiscalizadas}

El penúltimo párrafo del artículo 79 constitucional, antes de la reforma de 2008, prescribía, de forma sencilla y terminante, el necesario auxilio que los poderes de la Unión y los sujetos de fiscalización deberían proporcionar a requerimiento de la Auditoría Superior de la Federación, en los términos comunes del derecho constitucional mexicano, sin la previsión de sanción alguna.

Como quedó expuesto en el proceso legislativo de las reformas y adiciones, se hizo un recuento de las evasiones, incumplimientos y omisiones, en fin, la incuria de los sujetos fiscalizados (en especial de las entidades federativas), lo que obligó a enmendar las bases fundamentales de la colaboración y auxilio a las funciones de la Entidad de Fiscalización Superior de la Federación.

En tal virtud, fue forzoso señalar que en caso de desatender el auxilio debido a la Auditoría Superior de la Federación, por parte de los poderes de la Unión, las entidades federativas y demás entidades fiscalizadas, éstos podrán ser sancionados en los términos previstos por la Ley.

Además, se agregó que la obligación de proporcionar información y documentación a la Entidad de Fiscalización Superior de la Federación, a los servidores públicos federales y locales, así como cualquier entidad, persona física o moral, pública o privada, fideicomiso, mandato o fondo, o cualquier otra figura jurídica. La solicitud de información y de documentos deberá hacerse en los términos de los procedimientos que prevea la Ley, y sin perjuicio de la competencia de otras autoridades (con el fin de evitar que se esquive esta obligación de orden constitucional u otra que se desprenda del ordenamiento jurídico) y de los derechos de los usuarios del sistema financiero (como podría ser el secreto bancario y sus modalidades).

Oficial de la Federación del 1o. de diciembre de 2005) y 14, tercer párrafo, de la Ley Orgánica del Tribunal Federal de Justicia Fiscal y Administrativa (Diario Oficial de la Federación del 6 de diciembre de 2007). 
Lógicamente, el incumplimiento de esta obligación constitucional acarrea la posición de sanciones que el legislador secundario deberá plasmar en el ordenamiento indicado a detalle por el artículo 79 de la ley fundamental.

\section{EXPANSIÓN HACIA LOS ÁMBITOS LOCALES: LAS BASES CONSTITUCIONALES DE LA FISCALIZACIÓN PARA LOS ESTADOS Y EL DISTRITO FEDERAL}

Una acusada característica del federalismo mexicano ha sido definir instituciones para el ámbito de las entidades federativas mediante reformas y adiciones a la ley suprema de la Unión, a fin de que los estados y, a veces, el Distrito Federal sean forzados a crearlas y adaptarlas.

Ha sido el caso de la reforma del artículo 116 que señaló de forma expresa la división de poderes para el ámbito constitucional local de los estados; ${ }^{22}$ la adición del apartado B en el artículo 102, por el que se crearon los organismos protectores de los derechos humanos; ${ }^{23}$ la reforma electoral de 1996, que instituyó las características esenciales de las instituciones encargadas de organizar los procesos electorales y de los tribunales competentes para dirimir las controversias en dicha materia, ${ }^{24}$ y la adición del segundo párrafo al artículo 113 del código político que fincó la responsabilidad patrimonial del Estado. ${ }^{25}$

El decreto de reformas y adiciones constitucionales de mayo de 2008 impuso a los estados y del Distrito Federal un marco institucional para las entidades de fiscalización locales, mediante modificaciones a los artículos 116 y $122 .{ }^{26}$

22 Diario Oficial de la Federación, 13 de marzo de 1987.

23 Diario Oficial de la Federación, 28 de enero de 1992.

24 Diario Oficial de la Federación, 22 de agosto de 1996.

25 Diario Oficial de la Federación, 14 de junio de 2002.

26 Se adicionaron los párrafos cuarto y quinto de la fracción II del artículo 116 y el tercer párrafo del inciso c) de la fracción $\mathrm{V}$, de la base primera del apartado $\mathrm{C}$ del artículo 122, además de reformarse el primer párrafo del inciso c), y el inciso e), ambos de la fracción V de la base primera del apartado C del artículo 122. 


\section{Bases comunes}

Las modificaciones incorporadas y comunes para los ámbitos locales fueron las siguientes:

a) Las entidades de fiscalización quedarán adscritas a las legislaturas locales y a la Asamblea Legislativa del Distrito Federal, consideradas como órganos con autonomía técnica y de gestión en el ejercicio de sus atribuciones y para decidir sobre su organización interna, funcionamiento y resoluciones.

b) Similar al contenido del nuevo párrafo segundo del artículo 79 constitucional, la función fiscalizadora de las entidades federativas se desarrollaría conforme a los principios de posterioridad, anualidad, legalidad, imparcialidad y confiabilidad.

c) Se fija que los titulares de las entidades fiscalizadoras de las entidades fiscalizadoras locales deberán ser electos por los órganos legislativos, mediante la votación calificada de las dos terceras partes de los miembros presentes en dichos órganos. La duración de la gestión de los titulares no podrá ser menor a siete años, por lo que se respeta la autonomía de las entidades federativas para definir plazos más amplios, así como la posibilidad de establecer que los titulares puedan o no volver a ocupar dichos cargos.

d) También es impuesto como requisito mínimo el de contar con una experiencia de cinco años en materia de control, auditoría financiera y de responsabilidades, para ocupar el cargo de titular de la entidad local de fiscalización.

Resulta notoria la omisión de referencia a la posibilidad de medios de defensa contra la imposición de sanciones y las resoluciones de las entidades locales de fiscalización, de forma similar a lo incorporado en el artículo 79 constitucional, mediante el decreto de reformas y adiciones de mayo de 2008, por lo que no sería posible que los tribunales de lo contencioso administrativo de los estados y del Distrito Federal, pudiesen conocer de las impugnaciones en sede jurisdiccional.

\section{Previsiones especiales para el Distrito Federal}

En el decreto de mayo de 2008 se establecieron tres cuestiones específicas para la entidad de fiscalización del Distrito Federal. La primera 
consiste en que dicho órgano será encabezado por un titular, esto es, se tratará de un órgano unipersonal, dejando atrás la posibilidad de una titularidad colegiada. ${ }^{27}$

En segundo término, se precisó la competencia de la Asamblea Legislativa del Distrito Federal para expedir leyes que organicen la hacienda pública, el presupuesto, la contabilidad, el gasto público y la entidad de fiscalización del Distrito Federal, señalando las características de este órgano y los principios de la función de fiscalización. ${ }^{28}$ Finalmente, se actualizaron las facultades de revisión de la cuenta pública de la Asamblea Legislativa del Distrito Federal, con los criterios establecidos en la ahora restablecida fracción VI del artículo 74 constitucional.

\section{ADECUACIONES AL RÉGIMEN DEL MANEJO DE RECURSOS ECONÓMICOS PÚBLICOS}

En un breve tiempo, el artículo 134 de la Constitución federal ha sido objeto de dos enmiendas. La última se dio con motivo de la reforma electoral de $2007 . .^{29}$

A fin de armonizar el conjunto de la reforma en materia de gasto y fiscalización, y de proporcionar más y mejores apoyos de fundamentación para el ejercicio de la función de fiscalización, tanto de la Federación como de los demás entes públicos que componen el sistema federal, respecto del manejo de los recursos económicos del Estado mexicano.

El primer párrafo del artículo 134 fue reformado para extender el ámbito orgánico de aplicación del precepto, abandonando la confusión de los conceptos "gobierno federal" y "gobierno del Distrito Federal", así como el reduccionismo de su interpretación hacia el ámbito administrativo.

27 La vigente Ley Orgánica de la Contaduría Mayor de Hacienda de la Asamblea Legislativa del Distrito Federal, publicada en la Gaceta Oficial del Distrito Federal del 8 de febrero de 1999, en su artículo 10 establece que el órgano superior de dirección de la Contaduría Mayor se integrará por tres miembros con el carácter de contadores de entre los cuales uno tendrá el carácter de presidente.

28 Inciso e), de la fracción V, de la base primera, del apartado C del artículo 122 de la Constitución Política de los Estados Unidos Mexicanos.

29 Diario Oficial de la Federación del 13 de noviembre de 2007. 
La innovación extensiva consiste en regular el uso de los recursos económicos por parte de la Federación, los estados, los municipios, el Distrito Federal y los órganos político-administrativos de sus demarcaciones territoriales. Esto significa una considerable amplitud de sujetos obligados a acatar el contenido de este mandamiento constitucional. Quedan obligados todos los entes públicos del sistema constitucional de los Estados Unidos Mexicanos a acatar los principios de eficiencia, eficacia, economía, transparencia y honradez, con miras a satisfacer los objetivos a los que están destinados.

De igual forma, los órganos creadores de planes y programas, así como de los proyectos presupuestales; los encargados de aprobar presupuestos, y las entidades encargadas de la vigilancia, fiscalización y disciplina, de todo el espectro constitucional mexicano quedan sujetos a los mandamientos contenidos en el primer párrafo del artículo 134 de la ley fundamental.

En el mismo primer párrafo se agregan los principios de economía y transparencia que deben regir en la administración de los recursos públicos. El principio de economía significa que el uso de los recursos económicos públicos debe darse de forma racional, planeada, metódica y alejada de dispendios. Buena parte de este principio se ve consolidado con la reforma a la fracción XXVIII del artículo 73 constitucional, que trata de ordenar desde una perspectiva nacional a los entes públicos componentes de la República.

Atenta a la tendencia creciente en el ordenamiento mexicano, ${ }^{30}$ la reforma al artículo 134 impone que todos los órganos del Estado encargados de la administración de los recursos económicos públicos deben exponer públicamente la forma en que se ha practicado dicha administración, a fin de honrar el principio de transparencia. Este principio incorporado en el artículo 134 tiene una concordancia con los principios y bases enumeradas en el artículo 6o. de la misma Constitución federal, en especial con sus fracciones IV, V y VI.

30 En especial, con la reforma constitucional publicada en el Diario Oficial de la Federación del 20 de julio de 2007, que estableció, al máximo nivel normativo, las bases y principios del ejercicio del derecho de acceso a la información pública. Cfr. Carbonell, Miguel, Constitución Política de los Estados Unidos Mexicanos comentada, México, Porrúa-Comisión Nacional de los Derechos Humanos-UNAM, 2008, pp. 74-82. 
Se adiciona un segundo párrafo, recorriendo la secuencia de los siete restantes. El nuevo contenido prescribe que los resultados del ejercicio de dichos recursos serán evaluados por las instancias técnicas de la $\mathrm{Fe}$ deración, los estados y el Distrito Federal, "con el objeto de propiciar que los recursos económicos se asignen en los respectivos presupuestos en los términos del párrafo anterior", sin menoscabo de lo dispuesto en los artículos 74, fracción VI, y 79 de la Constitución.

De lo anterior se desprende la necesidad de instaurar dichas instancias técnicas encargadas de evaluar el desempeño en el manejo de los recursos económicos y, también, en el alcance de los objetivos, previstos en los planes, programas y presupuestos. En obviedad del principio de economía contenido en este artículo 134, lo ideal sería que no sean creadas ex profeso dichas instancias, sino que sean aprovechados los órganos internos de control o áreas de control de manejo financiero ya existentes, a fin de no procrear más entes administrativos dedicados a cumplir este segundo párrafo, echando por la borda el citado principio de economía, agregado en el párrafo primero del artículo 134.

El escueto párrafo cuarto, ahora recorrido como quinto, fue enriquecido en cuanto a su aplicación, por lo que hace a su ámbito orgánico y al ámbito jurídico. El anterior texto preveía genéricamente que el manejo de los recursos económicos federales se sujetaría a las bases del artículo 134. La nueva disposición se dirige a precisar el manejo de los recursos federales por los estados, los municipios, el Distrito Federal y sus delegaciones. Además, amplía el régimen al que quedarán sujetos: tanto a las bases normativas del propio artículo 134, como a las leyes reglamentarias, entendiéndose por éstas, tanto a las que desarrollen a detalle dicho artículo como las reglamentarias de otros preceptos fundamentales relacionados con la materia (por ejemplo, las que emita el Congreso de la Unión para reglamentar las fracciones IV y VI del artículo 74 o el artículo 79).

En concordancia con el nuevo segundo párrafo, en este párrafo quinto se prevé que la evaluación sobre el ejercicio de dichos recursos se realizará por las instancias técnicas de las entidades federativas, sin que ello signifique disminución de las atribuciones de las respectivas entidades locales de fiscalización.

Con reconocimiento de la teleología de las iniciativas que culminaron en este cúmulo de reformas y adiciones en materia de gasto público y fiscalización, se pudieron incorporar finalidades de tipo social, como parte 
del proceso de evaluación, a fin de evitar tendencias de corte contable, apreciables mas no únicas.

\section{CONCLUSIONES}

De lo expuesto en el presente estudio, se obtienen las siguientes conclusiones:

Primera. Las reformas y adiciones a diversos preceptos de la Constitución Política de los Estados Unidos Mexicanos en materia de gasto público y fiscalización, son producto de un proceso de revisión constitucional, donde no sólo se toma en cuenta la iniciativa del Poder Ejecutivo, sino que, como en otros casos trascendentes de enmienda a la ley suprema, también se valoran aportaciones surgidas del interior del Poder Legislativo, a fin de buscar coincidencias, que permitan mejorar los proyectos de lo que será convertido en letra constitucional.

Segunda. La iniciativa de reformas y adiciones constitucionales del Ejecutivo federal formaba parte de una amplia reforma en materia financiera, con lo que se buscaba la modernización de las finanzas públicas del país. A esta propuesta se sumó el proyecto que ya discutía el Poder Legislativo, a partir de una iniciativa de la senadora Georgina Trujillo, que trataba de homogeneizar los sistemas de fiscalización de las entidades federativas, así como prever que los entes de fiscalización quedarán insertos en los poderes legislativos de los estados y en la Asamblea del Distrito Federal.

Tercera. En términos generales, podemos decir que las reformas y adiciones en materia de gasto y fiscalización procuraron establecer bases constitucionales para enfrentar contingencias políticas en el momento de discutir el Presupuesto de Egresos de la Federación; consolidar el aparato institucional encargado de la fiscalización superior de la Federación, así como los correspondientes de las entidades federativas, y sentar mejores reglas dedicadas a la administración de todos los recursos públicos, ya no únicamente los que estén asignados a la Federación y al Distrito Federal, sino de forma extensiva a los recursos económicos públicos de los Estados, los municipios y los órganos político-administrativos de la sede de los poderes de la Unión.

Cuarta. El Congreso de la Unión fue dotado de una facultad legislativa de amplios alcances en el sistema federal mexicano: expedir leyes para la Federación, los estados, los municipios, el Distrito Federal y sus 
órganos político-administrativos de sus demarcaciones territoriales, sobre contabilidad gubernamental en materia de contabilidad pública y la presentación homogénea de información financiera, de ingresos y egresos, así como patrimonial. Dicha facultad tiene un perfil de tipo nacional, diferente a las facultades concurrentes y a las coincidentes, pues el Poder Legislativo federal se superpone a todos los componentes del sistema federal. De esta forma se crea un cuerpo normativo hermético, que permita una base contable y metodológica común para los entes públicos, sin excepción, lo que además redundará en mejorar la evaluación y fiscalización, especialmente cuando estén involucrados recursos económicos federales. De esta forma, la nueva potestad legislativa se vincula con las reformas y adiciones en materia de fiscalización y de administración de recursos económicos públicos, integrantes del mismo decreto publicado en mayo de 2008.

Quinta. En cuanto a las facultades exclusivas de la Cámara de Diputados, se previó la posibilidad de que se autoricen en el Presupuesto de Egresos de la Federación, erogaciones plurianuales dirigidas a proyectos de inversión en infraestructura, más allá del esquema constitucional clásico de la anualidad presupuestal, a efecto de que sean incluidas en los subsecuentes presupuestos de egresos de la Federación, con lo que también se superan posibles bloqueos de parte de la Cámara que impidan la continuidad de obras de mediano alcance, durante una gestión presidencial, en vista de la falta de mayorías legislativas favorables al Poder Ejecutivo en los últimos doce años.

Sexta. También se decidió, por el órgano revisor de la Constitución federal, que debería distinguirse la facultad de la Cámara de Diputados de revisar y aprobar la cuenta pública, anteriormente contenida en la fracción IV del artículo 74 constitucional, estableciéndose en la rehabilitada fracción VI. Conforme a la nueva previsión constitucional, la Cámara de Diputados evaluará los resultados de la gestión financiera y verificará el cumplimiento de los objetivos de los programas; se redujo la fecha para la presentación de la cuenta pública; asimismo, se determinó un límite temporal para que la Cámara concluya la revisión de la cuenta pública; quedó fijado que la ampliación del plazo para presentar la cuenta pública no deberá exceder 30 días naturales y que, por lo tanto, la Entidad de Fiscalización Superior contará con el mismo tiempo adicional para la presentación del informe del resultado de la revisión de la cuenta pública. Finalmente, la revisión de la cuenta pública debe considerar el análisis de 
su contenido y de las conclusiones técnicas del informe del resultado que emita la Entidad de Fiscalización Superior.

Séptima. Con la finalidad de fortalecer la función fiscalizadora del Poder Legislativo federal, una porción considerable del decreto de reformas y adiciones a la Constitución, en especial a su artículo 79, estuvo dedicada a expandir el conjunto de atribuciones de la Entidad de Fiscalización Superior de la Federación, o sea la Auditoría Superior de la Federación, órgano técnico de apoyo a la Cámara de Diputados para el mejor desempeño de su función de revisión de la cuenta pública, además de enumerar un conjunto de principios que deberán regir la función fiscalizadora (posterioridad, anualidad, legalidad, definitividad, imparcialidad y confiabilidad); también se definieron nuevas fechas para la presentación de la cuenta pública ante la Cámara de Diputados, para que la Auditoría Superior de la Federación entregue el informe del resultado de revisión a dicha Cámara y para que ésta concluya la revisión de la cuenta pública, sin menoscabo de que el trámite de las observaciones, recomendaciones y acciones promovidas por la Auditoría Superior de la Federación, sigan su curso.

Octava. De igual forma, al artículo 79 de la ley fundamental le fue adicionado el sistema de medios ordinarios de defensa contra la imposición de sanciones y las resoluciones emitidas por la Auditoría Superior de la Federación, lo que viene a constituir una excepción a la división de poderes, pues en caso de impugnar en sede jurisdiccional dichas determinaciones, resultaría que el Tribunal Federal de Justicia Fiscal y Administrativa asumirá la competencia para conocer de las demandas promovidas por las entidades fiscalizadas y por los servidores públicos afectados.

Novena. Fue necesario que mediante la reforma al octavo párrafo del artículo 79, se aclarase la indispensable colaboración que las entidades fiscalizadas deben prestar a la Auditoría Superior de la Federación, de la forma más amplia, sujetándose a las condiciones y procedimientos que la ley reglamentaria establezca, así como que dicho ordenamiento enumere las sanciones que correspondan por el incumplimiento a este imperativo constitucional.

Décima. Inserto en la tendencia creciente de los procedimientos de reformas y adiciones a la Constitución de procurar una homologación institucional, el decreto publicado en mayo de 2008 extiende sus alcances a los ámbitos de las entidades federativas, a fin de que, por lo menos, sus respectivas entidades locales de fiscalización sean dotadas de auto- 
nomía técnica y de gestión; de que su función se rija por los principios de posterioridad, anualidad, legalidad, imparcialidad y confiabilidad; que las entidades sean encabezadas por personas con experiencia en materia de control, auditoría financiera y de responsabilidades, además de ser electas mediante una mayoría calificada de las dos terceras partes de los miembros presentes de los poderes legislativos locales y de la Asamblea Legislativa del Distrito Federal. También es impuesta por la Constitución la duración mínima de siete años de los periodos de la gestión de los titulares de las entidades locales de fiscalización.

Décima primera. Es trascendente la reforma del artículo 134 constitucional, pues extiende su aplicación a los estados, los municipios, el Distrito Federal y sus órganos político-administrativos de las demarcaciones territoriales, además de la Federación, en lo tocante a la administración de sus recursos económicos, así como agregar dos principios más a los de eficiencia, eficacia y honradez que deben regir esa administración: los de economía y transparencia.

Décima segunda. La teleología de esta reforma consiste en racionalizar el uso de los recursos económicos públicos; superar la opacidad en el manejo de los recursos públicos, y fortalecer los fundamentos de dicho uso, así como de las correspondientes funciones de fiscalización y de determinación de responsabilidades. Además, es incorporada la referencia de las instancias técnicas encargadas de la evaluación de los resultados del ejercicio de los recursos públicos económicos.

Décima tercera. Podemos decir que el conjunto de la reforma constitucional en materia de gasto y fiscalización tiene aspectos positivos en términos generales, con la finalidad de que sean debidamente aprovechados los recursos económicos públicos; que el Congreso de la Unión, sea como Poder Legislativo o por conducto de la Cámara de Diputados, tenga facultades mejor detalladas, dentro de un esquema de equilibrio, colaboración y control de los poderes federales; que se fortalezcan las entidades de fiscalización, sin descuidar que deben conducirse dentro del perímetro de la legalidad, y que sea establecido un marco jurídico desde la ley suprema de toda la Unión, mucho más detallado y adecuado para la realidad política por la que México ha transitado desde 1997. 